\title{
Design and Analysis of Solar Tree
}

\author{
D Rambabu $^{1}$ | K Pavitra ${ }^{1}$ | A Sai Lokesh ${ }^{1} \mid$ K Gowtham ${ }^{1} \mid$ K Suneel Gowtham ${ }^{1}$ \\ ${ }^{1}$ Department of EEE, Aditya Institute of Technology and Management, Tekkali, Andhra Pradesh, India.
}

\section{To Cite this Article}

D Rambabu, K Pavitra, A Sai Lokesh, K Gowtham and K Suneel Gowtham, "Design and Analysis of Solar Tree", International Journal for Modern Trends in Science and Technology, Vol. 06, Issue 07, July 2020, pp.:85-90; https://doi.org/10.46501/IJMTST060713

\section{Article Info}

Received on 19-June-2020, Revised on 22-June-2020, Accepted on 30-June-2020, Published on 13-July-2020.

\section{ABSTRACT}

As a convention energy sources depleting from the earth and as it harms the environment is moving towards non-conventional energy sources. In this paper, a product known as solar tree is introduced which requires less space than other conventional energy equipments space availability is the main problem in cities. Solar tree has been designed to increase the power output by many folds by consuming solar energy. It can be installed on the sides of the roads. The tree consists of numerous solar panels connected to one another in series and parallel connection. The solar tree consists of number of branches welded to a stem and each stem has a solar panel mounted on it. It adds up voltage in series and current in parallel connection. it lights up a CFL lamp continuously for much time.

KEYWORDS: solarpanels, LED lights, batteries, cables.

Copyright (C) 2014-2020 International Journal for Modern Trends in Science and Technology DOI: https://doi.org/10.46501/IJMTST060713

\section{INTRODUCTION}

Renewable Energy Resources is a numerate and quantitative text covering subjects of proven technical and economic importance worldwide. Energy supplies from renewable (such as solar, thermal, photovoltaic, wind, hydro, bio fuels, wave, tidal, ocean and geothermal sources) are essential components of every nation's energy strategy, not least because of concerns for the environment and for sustainability. It is a form of renewable energy resource that is some measure competitive with fossil fuels. Hydro power is the force of energy of moving water. It provides about $96 \%$ of the renewable energy in the United States. Hydroelectric power plants do not use any resources to create electricity or they do not pollute the air. The sun is a hydrodynamic spherical body of extremely hot ionized gases (plasma), generating energy by the process of the thermonuclear fusion. The temperature of interior of sun is estimated at
$8^{*} 10^{\wedge} 6 \mathrm{k}$ to $40^{*} 10^{\wedge} 6 \mathrm{k}$, where energy is released by fusion of hydrogen and helium. Solar energy is available in abundance and considered as the easiest and cleanest means of tapping the renewable energy. For direct conversion of solar radiation into usable form, the routes are: solar thermal, solar photovoltaic and solar architecture. However the main problem associated with tapping solar energy is the requirement to install large solar collectors requires a very big space. To avoid this problem we can install a solar tree in spite of a no of solar panels which require a very small space. There are many types of Renewable Energy Sources such as Wind Power, Tidal Power, Solar Power, Geo-Thermal Power, Thermo-Electric Power, Ocean Thermal Energy (OTE),Biogas/Biomass, Fuel Cells. Solar energy is better than other renewable energy sources because there is a variety of energy sources besides the sun, but the selection of solar power are easily 
made apparent when measured against other methods.

The reduced environmental impact of using solar energy in comparison to fossil fuels and other non-renewable resources has been noted and lauded. Understanding how solar energy works is important, since its benefits are unfortunately rarely compared to other green and sustainable sources. Hydroelectricity, wind turbines, geothermal energy and biomass are all environmentally friendly alternatives to traditional fuels. Hydroelectricity, although effective, does not benefit home usage since it is generally supplied through the use of large dams. Not only are dams expensive to build, but there are also many details to take into account before building one and the impact of the surrounding environment should be evaluated. Building a dam has the ability to alter an entire ecosystem and must be done with proper care and consideration. Photovoltaic panels will not change the environment and are small in comparison to dams. One of the advantages of solar power is its versatility. A land or roof installation can be set up in regions that many would think don't receive enough sunlight. Wind turbines can be another effective way to generate energy, but the advantages of solar power prevail over this method as well. Although the initial power gathered from wind is less expensive to produce, wind turbines require much more maintenance than photovoltaic cells. They are also more disruptive than their solar counterpart, since they are prone to making lots of noise. While PV panels can be installed on rooftops, a wind turbine is better suited for open and spacious areas. Traditionally, geothermal energy is restricted from becoming widespread by its reliance on being near tectonic plates. Advancements in technology may make geothermal energy more accessible in the future. Currently, another of the advantages of solar power is that it is effective anywhere in the United States. The use of biomass, such as the burning of wood, waste, alcohol fumes, or landfill gases produces less waste energy than fossil fuels or coal. Unfortunately, biomass creates volatile organic compounds, carbon monoxide and nitrogen oxides. On the positive side, its pollution is modest in comparison to traditional fuels. Photovoltaic cells prove superior again in that they create no emissions and do not require land that could be used for crops. The aforementioned green energy sources are better than fossil fuels and beneficial to taking some of the strain off the environment. The sustainable energy gained from the sun is still superior in quite a few areas. Solar energy can be used for large installations. It can also be created for a smaller scale and affordable enough for home use. Once installed, a home energy system requires very little upkeep, adjustment or maintenance. While dams and wind turbines have to be placed with consideration to their effects on the surrounding area, PV panels only need to be set up with the areas that receive the most sun. Unlike bio fuel and wind turbines, sun power does not create pollution or noise. Research suggests that there are advantages of solar power over any of its competition. The main aim of this project is to build an array of solar panels by installing the panels on a welded stem to a pole. The tilt angle of solar panel and other parameters suitably depend on the coordinates of local area of installation. The Solar panels having the solar cells. These solar cells having optimum operating point to be able to get the maximum power. To obtain maximum power from PV array. Photovoltaic power system usually requires maximum power point tracking controller. With depleting conventional sources of energy the world is looking for renewable energy sources like solar, wind..etc., solar energy is the best option when we looking for non-conventional energy sources. Because it is very easy to trapped the solar radiations and convert it into electrical energy by using Photovoltaic cells. Now it is necessary to think about the environment by reducing pollution. So solar energy is the best option when we consider all the above mention parameters. The only problem occurs when we use solar energy is that a large space is required for a large panels for higher outputs. So it can be solved by this new product known as "Solar Tree". This paper finds every aspect of the solar tree to work efficiently than other conventional methods of harnessing solar energy by solar panels. The solar tree will provide electrical energy in areas where electrical grid is not reached yet, and hence can lighten up many homes with affordable price. The renewable energy sources generates electrical energy efficiently without any impact on the environment. The idea of the solar tree is a new method for installing the solar panels in various angles and position on a tree like structure thus saving a huge amount of space when installing it by conventional method. The tree made is like real life tree that consists stem, multiple branches and solar panels as leaves. The main pole consists all the electronics 
components and then multiple branches grows out of the tree, on that branches multiple solar panels are mounted for harnessing maximum solar energy. The solar panels are mounted in such a way that each solar panel gets maximum solar irradiation from the sun and generates maximum power output. The solar tree will only take $1 \%$ of the area in comparison with the land that is required by the conventional installation of the PV panels. Since price of land is increasing day by day in almost every country the solar tree will drop down the installation price of the PV panels in comparison with the land. the usable land that can be used as a cultivating field is going to be more costly than in the coming future. There are many ongoing projects that are undertaken by the government and are facing many issues regarding the acquisition of the land. Hence there is a need for a device or a method or a system for providing efficient and maximum power from a defined space of area, without utilizing much area generating economical revenue. Solar Tree or Solar Photovoltaic Trees are a solar structure that looks like trees. They can be framed from small scale like a bonsai tree to large scale like the size of the wind turbine. It is a solar artwork which is a combination of artistic and technological effort. This is relatively new concept is conceived in an attempt to use new technology relating to harvesting and use of solar energy. In solar trees, PV panels or cells are arranged in a Fibonacci series pattern instead of leaves. The solar tree produces more power than a conventional flat arrangement of solar cells. It requires only $1 \%$ land as compared to the conventional flat arrangement. The panels of flat mounting for homes are inefficient, as the angle of sun's rays is not constant, particularly during the changes in seasons. Some residential solar systems are designed to track the sun but these systems increase the cost of solar energy because they are expensive and require maintenance.

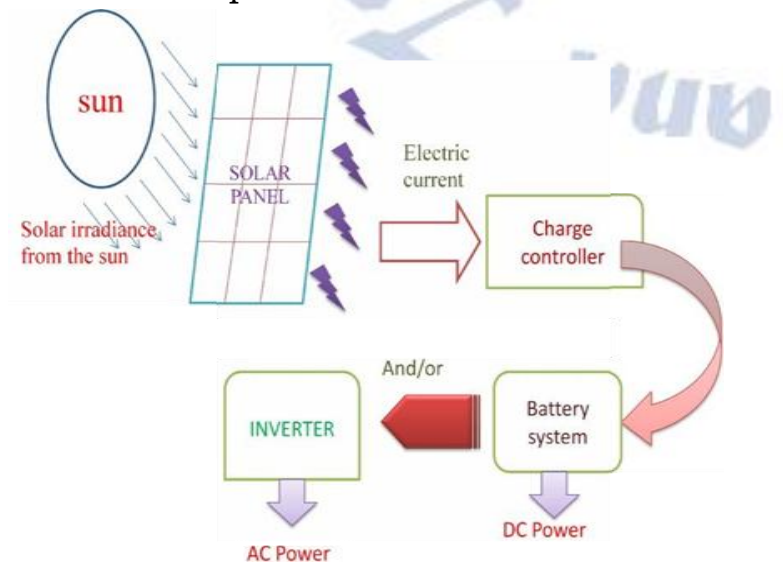

Figure 1: Block Diagram

These solar trees have been designed to provide different means of power to different urban and built environments. These ranges from powering mobile phones, electric cars, buildings and street lighting and covering large and small scale area. Solar trees are really a practical solution for urban street lighting. There is a rapid increase in the use of PV systems in India due to continuous reduction in prices of solar cells. But there are some hurdles for adoption of this technology in rural and remote areas due to the security of the system and its components from theft. Most of the rural street lighting PV system installed by the government is not in working conditions because of above-mentioned reasons and lack of maintenance. Hence presently PV systems prove to be suited mainly for urban \& corporate use. Still, there is less response for use of PV system for domestic applications due to higher initial cost and area required for mounting such systems. In this context use of PV technology for the domestic requirement in the form of the solar tree is the good alternative as compared to conventional flat or rooftop mounting. Solar trees can be installed near, in front of the house or on a terrace, where there is no shading throughout a day. This paper illustrates design and development Solar Tree for domestic application considering the average requirement of small Indian house.

\section{WORKING PROPOSED METHOD}

\section{Solar tree:}

As we know trees are present in nature and they can produce their own food material by the process called PHOTOSYNTHESIS. It is the process by which the green plant collects energy from sun and the water present in soil at the day time and can produces their own food material. By this process they are indirectly providing food to the human society because we are depending on the green plants for our food directly or indirectly. Here we are considering the example for understanding about the solar tree. 


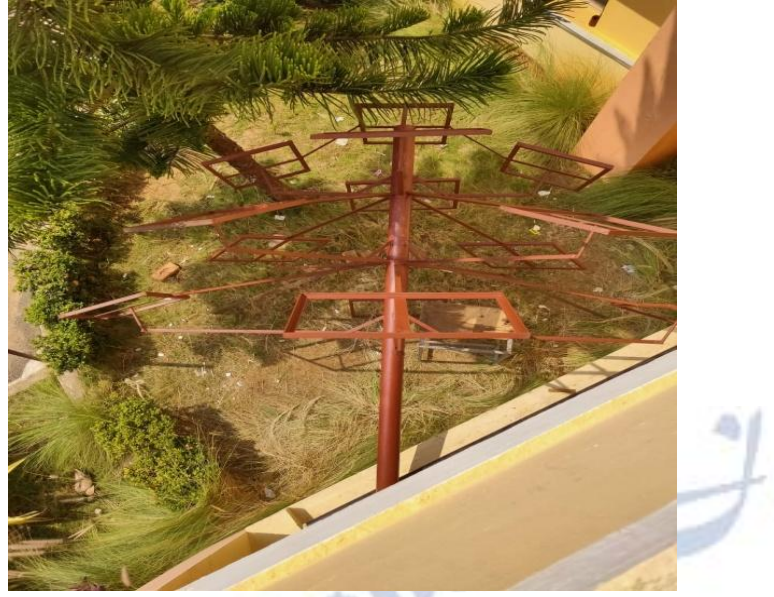

Figure 2: Structure of Solar Tree

This is a tree in which the stems connected acts as the branches of the tree and the solar panels are like the leaves. Green leaves are producing food materials for human beings likewise this leaves are producing energy for the society. So it is very appropriate to called it as a tree. It has same methods are used Spiralling Phyllataxy It is a technique used in designing of solar tree. It provides the way to help the lower panels from the shadow of upper ones, so that it can track maximum power from sun. Batteries are charged during the day time. LEDs are automatically switched on these are used to indicate how much charge/energy remain left Batteries are also used to store the energy so that we can use it at night and in cloudy days when no sunlight is there.

A light-emitting diode (LED) is a semiconductor light source. LEDs are used as indicator lamps in many devices and are increasingly used for other lighting. When a light-emitting diode is forward-biased (switched on), electrons are able to recombine with electron holes within the device, releasing energy in the form of photons. This effect is called electroluminescence and the color of the light (corresponding to the energy of the photon) is determined by the energy gap of the semiconductor. An LED is often small in area (less than $1 \mathrm{~mm} 2$ ), and integrated optical components may be used to shape its radiation pattern. LEDs present many advantages over incandescent light sources including lower energy consumption, longer lifetime, improved physical robustness, smaller size, and faster switching. LEDs powerful enough for room lighting are relatively expensive and require more precise current and heat management than compact fluorescent lamp sources of comparable output. Light-emitting diodes are used in applications as diverse as aviation lighting, automotive lighting, advertising, general lighting, and traffic signals. LEDs have allowed new text, video displays, and sensors to be developed, while their high switching rates are also useful in really be advanced communications technology. Infrared LEDs are also used in the remote control units of many commercial products including televisions, DVD players, and other domestic appliances. photons hit a solar cell, they knock electrons loose from their atoms. If conductors are attached to the positive and negative sides of a cell, it forms an electrical circuit. When electrons flow through such a circuit, they generate electricity. Multiple cells make up a solar panel, and multiple panels (modules) can be wired together to form a solar array.

\section{SCHEMATIC DIAGRAM OF SOLAR TREE}

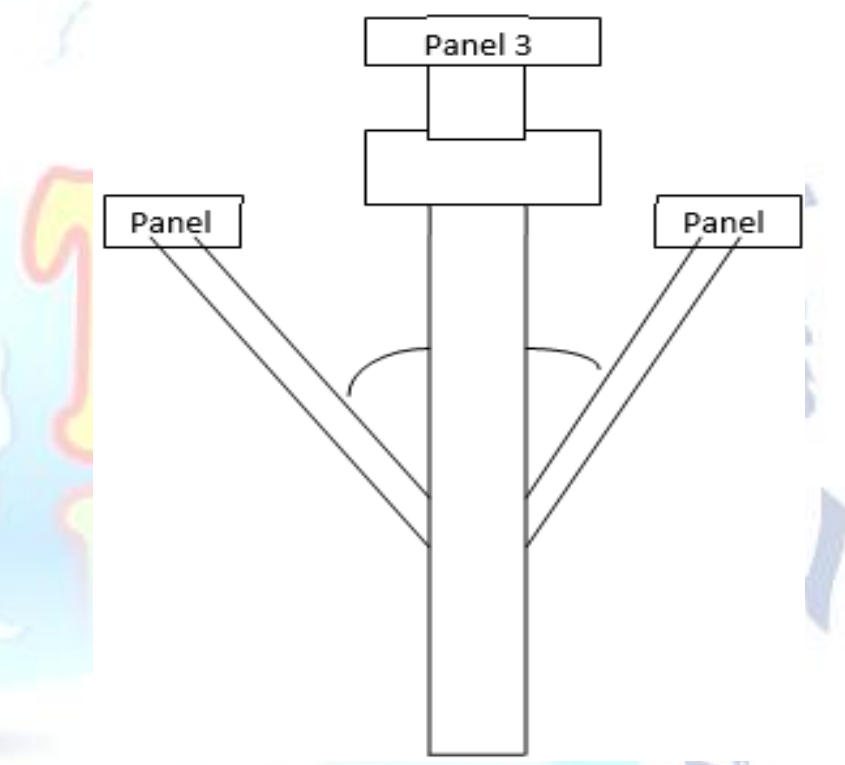

Figure 3: Schematic Diagram for Solar tree

The more panels you can deploy, the more energy you can expect to generate. Photovoltaic (PV) solar panels are made up of many solar cells.

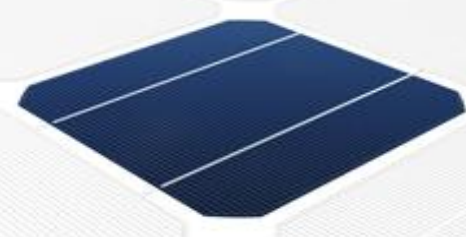

Figure 4: Structure of Solar Cell

Solar cells are made of silicon, like semiconductors. They are constructed with a positive layer and a negative layer, which together create an electric field, just like in a battery. PV solar panels generate direct current (DC) electricity. With DC electricity, electrons flow in one 
direction around a circuit. This example shows a battery powering a light bulb. The electrons move from the negative side of the battery, through the lamp, and return to the positive side of the battery. With AC (alternating current) electricity, electrons are pushed and pulled, periodically reversing direction, much like the cylinder of a car's engine. Generators create AC electricity when a coil of wire is spun next to a magnet. Many different energy sources can "turn the handle" of this generator, such as gas or diesel fuel, hydroelectricity, nuclear, coal, wind, or solar.AC electricity was chosen for the U.S. electrical power grid, primarily because it is less expensive to transmit over long distances. However, solar panels create DC electricity. How do we get DC electricity into the AC grid? We use an inverter. A solar inverter takes the DC electricity from the solar array and uses that to create $\mathrm{AC}$ electricity. Inverters are like the brains of the system. Along with inverting DC to AC power, they also provide ground fault protection and system stats, including voltage and current on AC and DC circuits, energy production and maximum power point tracking. Central inverters have dominated the solar industry since the beginning. The introduction of micro-inverters is one of the biggest technology shifts in the PV industry. Micro-inverters optimize for each individual solar panel, not for an entire solar system, as central inverters do. This enables every solar panel to perform at maximum potential.

When a central inverter is used, having a problem on one solar panel (maybe it's in the shade or has gotten dirty) can drag down the performance of the entire solar array. Micro-inverters, such as the ones in Sun Power's Equinox home solar system, make this a non-issue. If one solar panel has an issue, the rest of the solar array still performs efficiently. Here's an example of how a home solar energy installation works. First, sunlight hits a solar panel on the roof. The panels convert the energy to DC current, which flows to an inverter. The inverter converts the electricity from $\mathrm{DC}$ to $\mathrm{AC}$, which you can then use to power your home. It's beautifully simple and clean, and it's getting more efficient and affordable all the time. However, what happens if you're not home to use the electricity your solar panels are generating every sunny day? And what happens at night when your solar system is not generating power in real time? Don't worry, you still benefit through a system called "net metering."A typical grid-tied PV system, during peak daylight hours, frequently produces more energy than one customer needs, so that excess energy is fed back into the grid for use elsewhere. The customer gets credit for the excess energy produced, and can use that credit to draw from the conventional grid at night or on cloudy days. A net meter records the energy sent compared to the energy received from the grid. India is a highly populated country, so we should take the advantage of such an energy which requires a very less space to produce energy efficiently. In this case solar tree could be the best one for us. It is much better than the traditional solar PV system in area point of view and also more efficient. So this will be a very good option and should be implemented. For the traditional system we require large size of land to generate a small amount of power. It requires about $1 \%$ land as compare to the traditional system. Solar energy is available in abundance and considered as the easiest and cleanest means of tapping the renewable energy. For direct conversion of solar radiation into usable form, the routes are: solar thermal, solar photovoltaic and solar architecture. However the main problem associated with tapping solar energy is the requirement to install large solar collectors requires a very big space. To avoid this problem we can install a solar tree in spite of a no of solar panels which require a very small space. Example - To generate $2 \mathrm{MW}$ power from a pv module we requires $10-12$ acres of land for housing of panels only but for the same amount of energy we require only $0.10-0.12$ acres of land in case of solar tree

\section{EXPerimental Diagram and Results}

Total wattage of a solar panel is $500 \mathrm{w}$ wear as Battery rating is $150 \mathrm{AH}, 12 \mathrm{~V}$ and Inverter rating is $1 \mathrm{KW}$ we should use inverter up to $80 \%$ of load so, we can use the load up to $800 \mathrm{~W}$.

\begin{tabular}{|l|c|c|l|}
\hline LOAD & Wattage & Quantity & Total \\
\hline computer & $80 \mathrm{~W}$ & 6 & $\begin{array}{l}6 \times 80= \\
480 \mathrm{w}\end{array}$ \\
\hline Fan & $80 \mathrm{~W}$ & 4 & $320 \mathrm{w}$ \\
\hline Total load & $160 \mathrm{~W}$ & 10 & $800 \mathrm{w}$ \\
\hline
\end{tabular}





Figure 5: Experimental Diagram for Solar Tree

\section{Conclusion}

The solar tree concept is very successful to fulfil the increasing energy demand of the people, saving of land, and should be implemented in India to provide electricity without the problem of power cut-off and reduce the dependence on grid power. Daily average energy requirement of the small Indian family is calculated about $3.5 \mathrm{~kW}$. Such systems can be mounted on the terrace, in front of the house or near the wall avoiding shading areas. The initial investment cost of the solar tree is also equal to same capacity PV systems as other system components are similar. The overall cost of the domestic solar tree can be reduced by using the available local material. To reduce cost the design of tree structure should be simple and innovative. The performance (MPP) of solar tree better than conventional rooftop mountings as manual or low-cost auto tracking system can be easily incorporated. The same design procedure can be extended to other locations and applications involving higher energy consumptions. Government aid and financial support for PV system equipment installation are highly recommended. Collaborative research work amongst Chemists, Physicists and Engineers will resolve the problem. At the last Solar Tree shall not harm ecology and should work harmony with natural trees

\section{REFERENCES}

[1] J.A. Jakubiec, C. F. Reinhart, "A method for predicting citywide electricity gains from photovoltaic panels based on LiDAR and GIS data combined with hourly Daysim simulations," Sol. Energ., Vol. 93, pp. 127-143, Jul. 2013.

[2] Karl F. Warnick "A Bio-Inspired Patch Antenna Array Using Fibonacci Sequences in Trees", IEEE Antennas and Propagation Magazine Vol 55, no. 5, oct 2013.

[3] Abhishek Agarwal, Vineet Kumar Vashishtha, S.N. Mishra," Solar Tilt Measurement of Array for Building Application and Error Analysis", International Journal of Renewable Energy Research, IJRER, Vol. 2,No. 4,
[4] Immanuel Alphonse, Dr. S. HosiminThilagar, F. Bright Singh," Design of Solar Powered BLDC Motor Driven Electric Vehicle",International Journal of Renewable Energy Research

[5] Rustu Eke, SenerOktik," Seasonal Variation of Internal Parameters of an Amorphous Silicon(a-Si) Thin film Photovoltaic Module"International Journal of Renewable Energy Research2012

[6] .FarshidMostofi, Hossein Shayeghi," Feasibility and Optimal Reliable Design of Renewable Hybrid Energy System for Rural Electrification in Iran", International Journal of Renewable Energy Research, IJRER, vol.2, No.4, 2012.

[7] Markvart, T. Photovoltaic Solar Energy Conversion. Proceedings of the Energy for Europe. 7th - 14th July. Strabourg. 2002.

[8] P.Baruch. A two-level system as a model for photovoltaic solar cell. J. Appl. Phys. Vol 57. 1347. 1985.

[9] L.L.Bucciarielli. The effect of day -to-day correlation in solar radiation on the probability of loss of power in a stand - along photovoltaic energy systems. Solar energy. Vol 36. 11. 1986

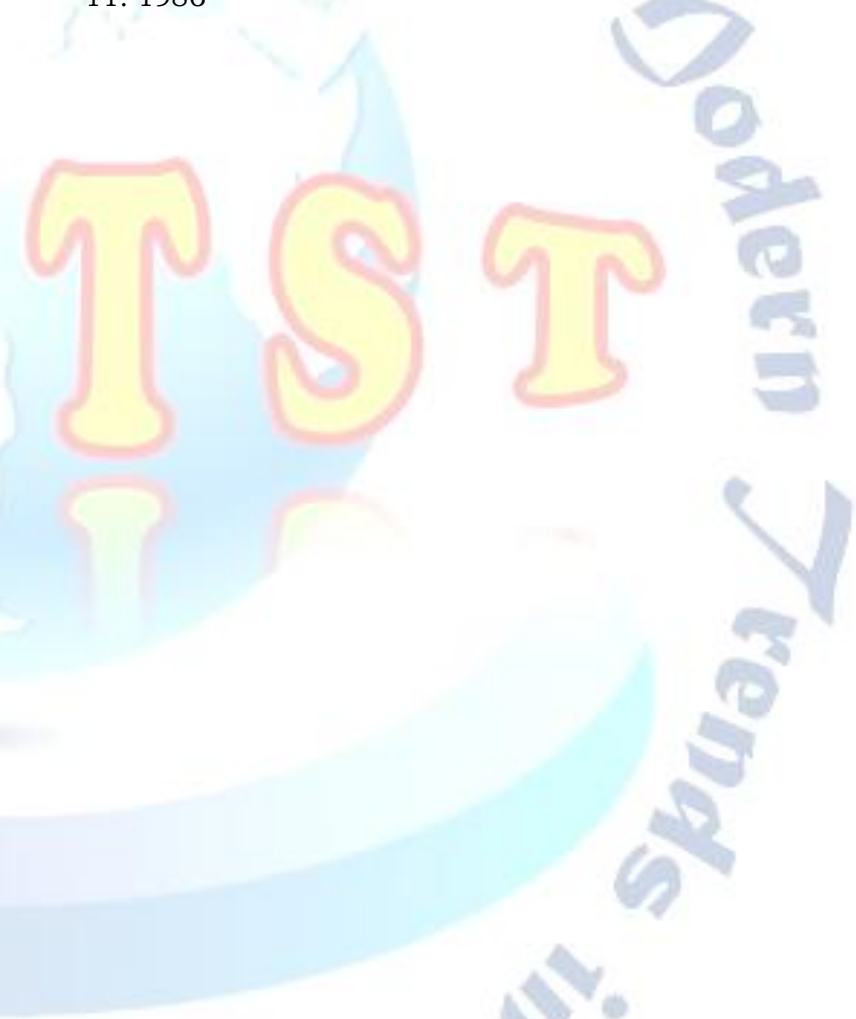

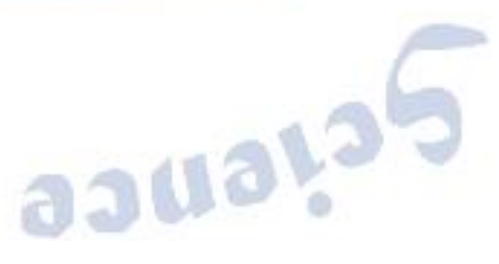

90 International Journal for Modern Trends in Science and Technology 